تأثير تركيب تربة التغطية وموعد إضافتها على إنتاجية الفطر الزراعي (عيش الغراب)

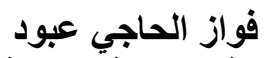

قسم البساتين، كلية الزراعة، جامعة الفرات، سوريا

الملخص:

أجري هذا البحث في بيت بلاستيكي خاص وذللك عام ه . . ب وكان الهذف الرئيسى منـه هو

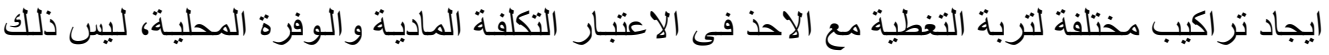

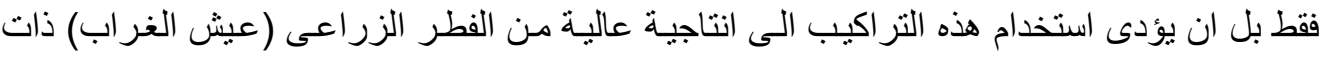
الصفات التسويقية الجيدة.

تم استخدام كومبوست مركب من قش القمح وذرق الدجاج و الجبس وقد دلت النتائج على انـه

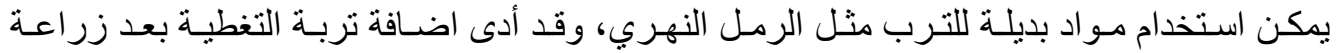
الميسيليوم مباشرة الى خفض انتاجية الفطر، كذلك فان افضل مو عد لاضافة نربة التغطية هو عـ أيوم من زراعة الميسيليوم وان مو عد اضافة تربة التغطية ليس لله أى تأثثير على الصفات الثكلية للاجسيسام الثمرية للفطر.

كلمات مفتاحية: تربة التغطية، ميسيليوم، فطر زراعي (عيش الغراب)، أجسام ثمرية مقدمة:

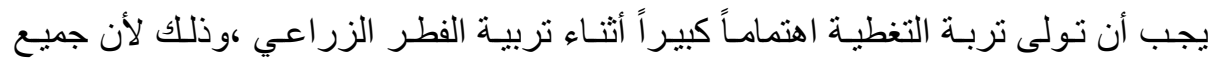

الأبحاث تشير إلى أنه بدون تربة تغطية لا تتشكل الأجسام الثمرية للفطر كو إذا ما تشكلت هذه التهبة الأجسـام


أثناء تركيب تربة التغطية يجب البحث عن مواد ذات سعة حقلية كبيرة ولها القدرة على الاحتفاظ

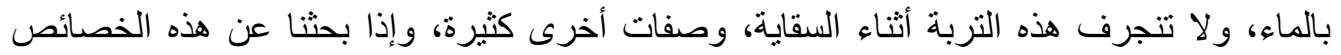

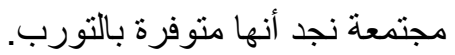
ولكن وبسبب ندرة مصادر التورب في بلدنا حيث أننا نستورد التورب باستمرار من الدول المتقدمة

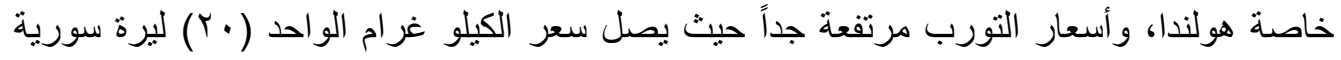
و هذا يشكل عبئ اقتصادي على بلدنا ومن هنا جاءت أهمية مشرو عنا تأثير تركيب ومو عد إضافة تربة

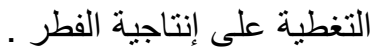
هدف البحث: :

تركيب تربة تغطية على أساس مواد رخيصة الثمن ومتوفرة بكثرة ( الرمل النهري ) تسمح بتقليل

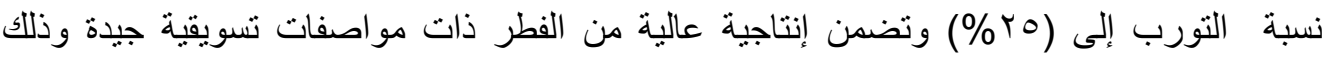

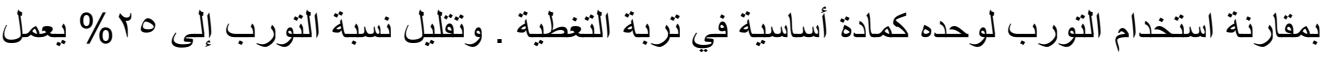

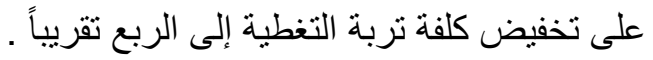
الأبحاث السابقة:

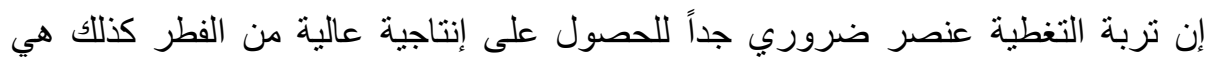
مركب هام في التقنية (التكنولوجيا) الزراعية للفطر الزراعي. إن غياب تربة التغطية يعمل على فئل

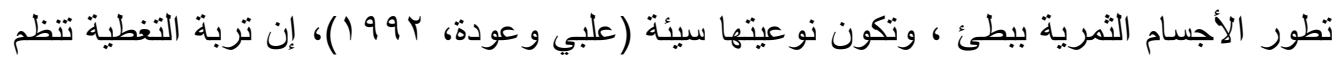

Fayoum J. Agric. Res. \& Dev., Vol.23, No.2, July, 2009 
ميكرومناخ الكومبوست وتساعد على تطور نوع من البكتريا لها تأثير ايجابي على تطور الأجسام الثمرية. وبشكل عام فان تربة التغطية تقوم بالوظائف التالية:

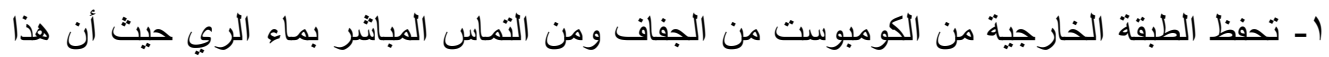
التماس المباثر يعمل على تعفن المسيليوم .

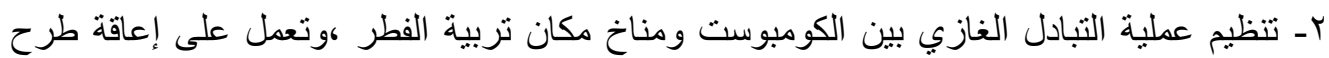

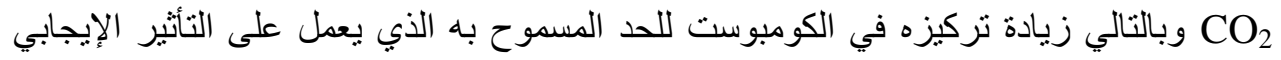

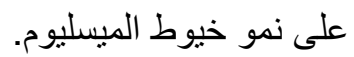

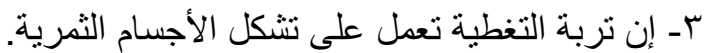

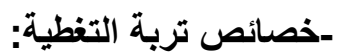
من الخصائص الفيزيائية و الكيميائية لتربة التغطية ما يلي :

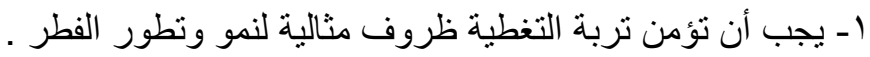

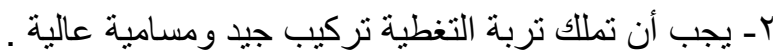
r- ك- أن لا تتحط أنثاء السقاية.

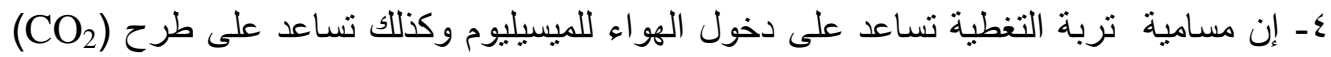

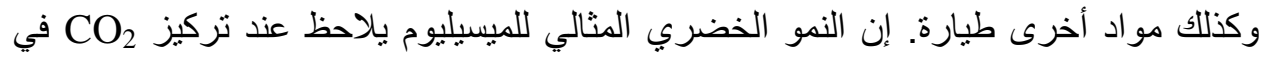

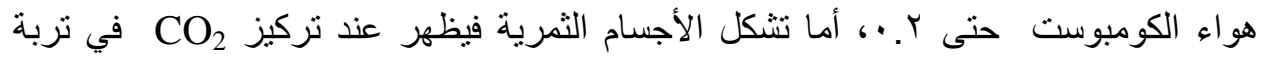

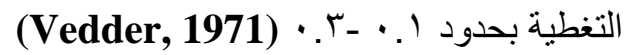

يلاحظ تحت ظروف التبادل الهو ائي الجيد لتربة التغطية مع الوسط المحيط أن غاز (

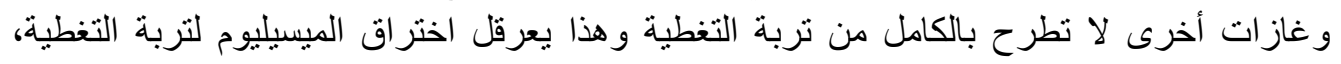

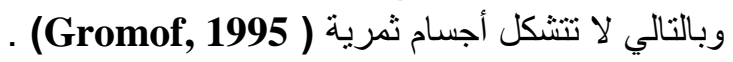

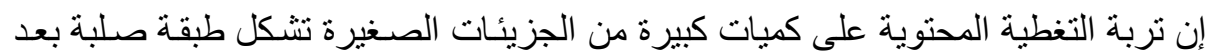

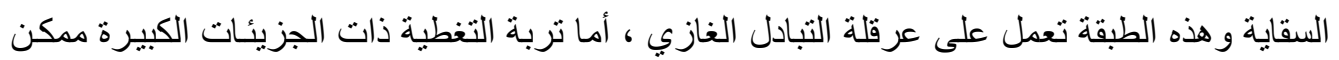


المحصول تتقطع خيوط الميسيليوم (Defoshken , 1975, 1989).

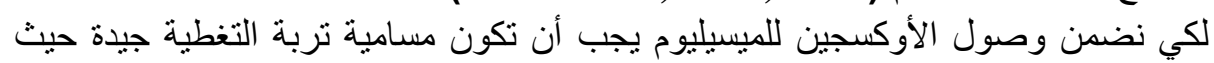

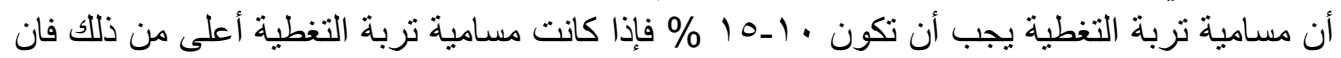

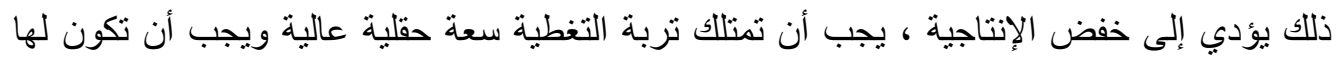
القدرة على امتصاص الماء و الاحتفاظ به بشكل تدريجي (Vedder, 1968).

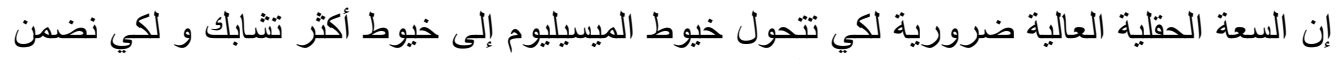

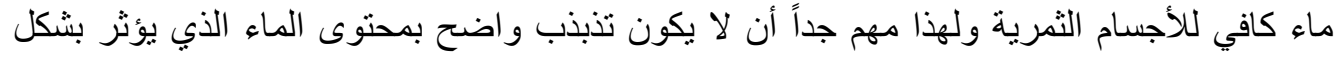
سلبي على نمو وتطور الميسيليوم وتشكل الأجسام الثمرية (Gromof, 1995). تحت ظروف السعة الحقلية المنخفضة فان تربة التغطية لا تضمن النظام المائي المطلوب للنية للمحصول

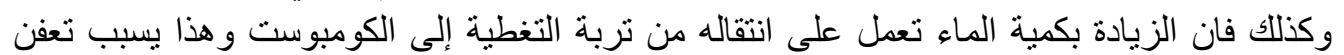
الميسيليوم وموته.

Fayoum J. Agric. Res. \& Dev., Vol.23, No.2, July, 2009 
إن تركيب تربة التغطية وخاصة حفظها للماء تسيء إذا كان محتوى الآزوت العضوي يزيد

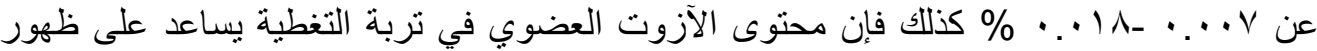
كمية كبيرة من الأجسام الثمرية الصغيرة والتي يموت أكثرها كما أن الأجسام الثمرية التي تظهر

تكون صغيرة وبسر عة تتفتح (Defoshken, 1975, 1989 ، Gromof, 1995). إن المحتوى الزائد من الأملاح في تربة التغطية يعمل على زيادة الناقلية الكهربائية لمحلول التربة و هذا يؤثر سلبا على إنتاجية الفطر.

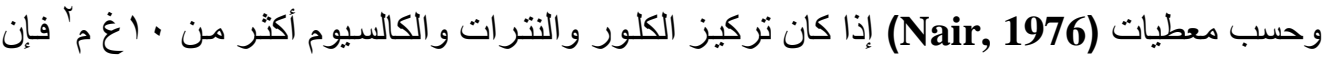

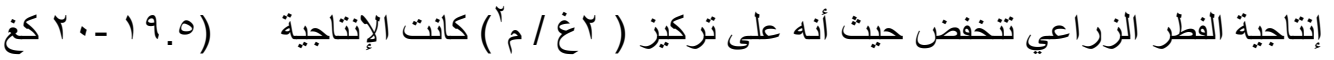

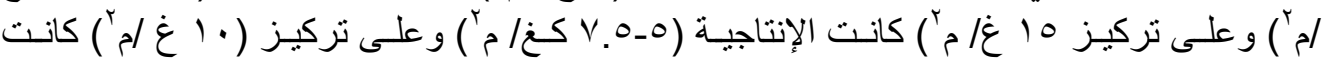

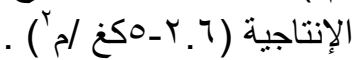

وفي حالة استخدام الكومبوست المستهلك بعدد الزراعة كتربة تغطية فإن إنتاجية الفطر

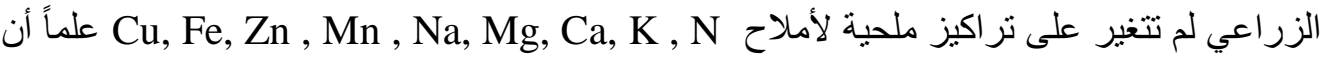

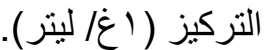
يفيد (Nair, 1977) بأن المحتوى الزائد من الآزوت في تربة التغطية يعمل على تأخير

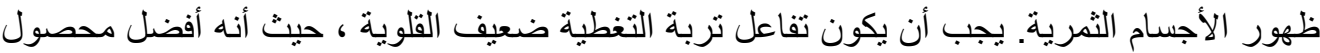

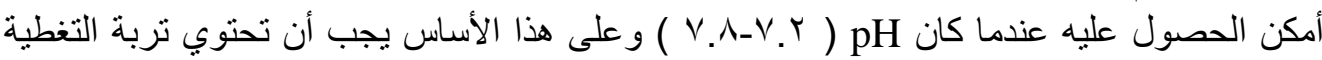

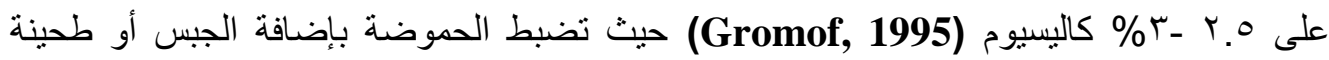

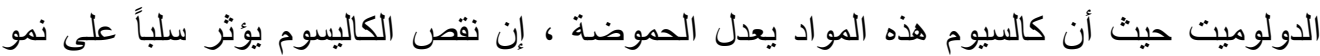

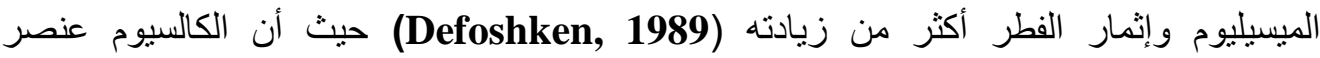

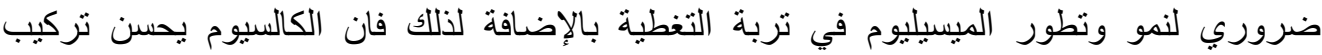

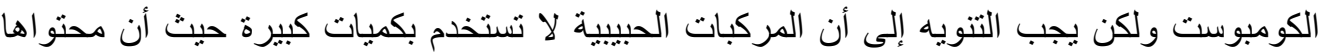

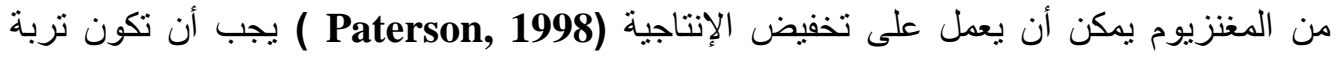

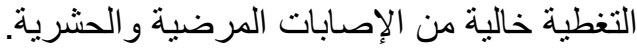

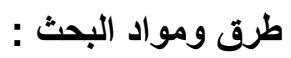

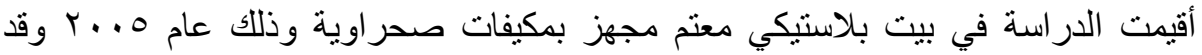

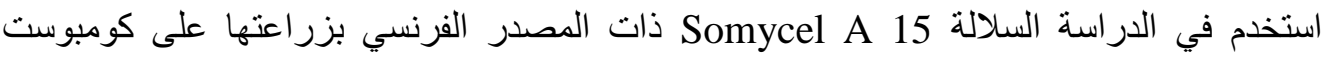

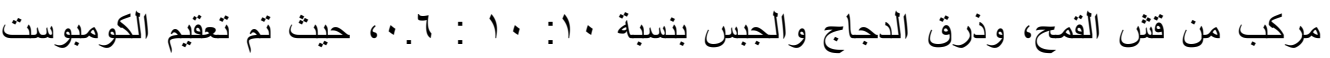

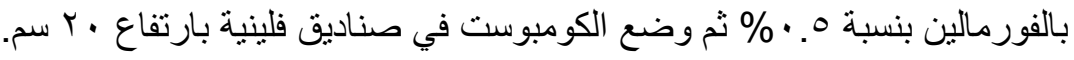

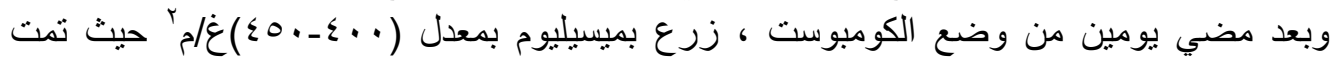

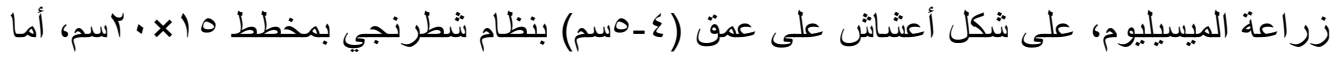

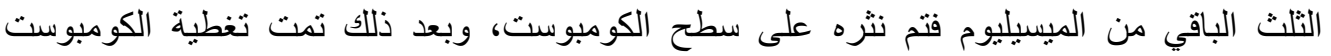

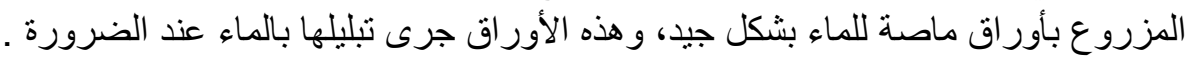

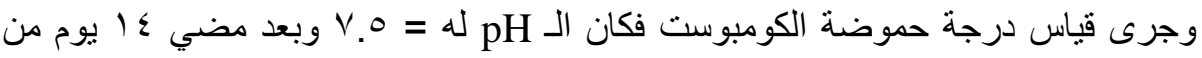

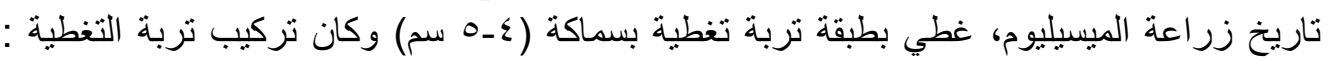

Fayoum J. Agric. Res. \& Dev., Vol.23, No.2, July, 2009 
التورب الأسود و الرمل النهري و الجبس وجرى تعقيم تربة التغطية بمحلول هـ ـ • فورمالين وذللك قبل

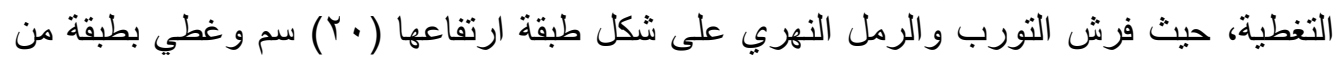

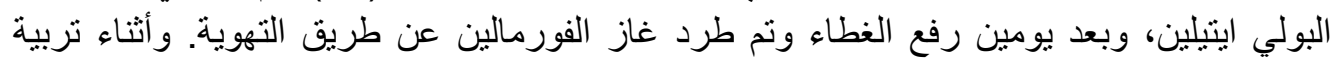

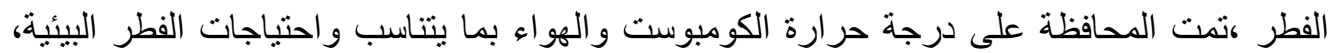

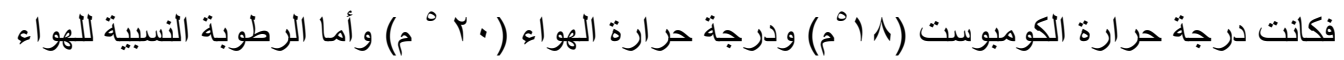

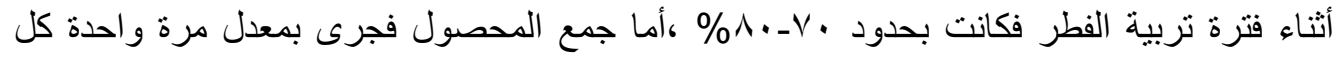

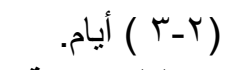

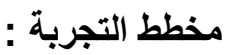

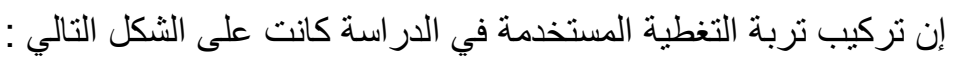

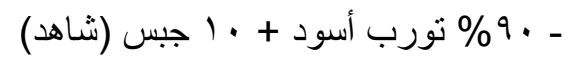

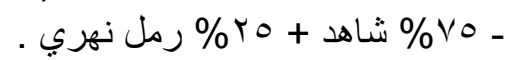

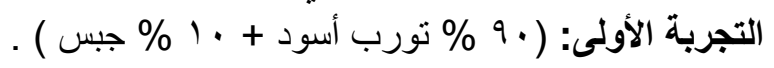

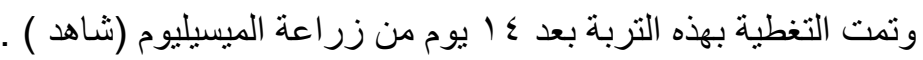

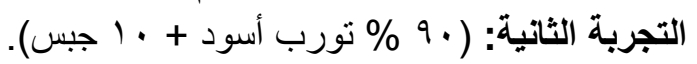

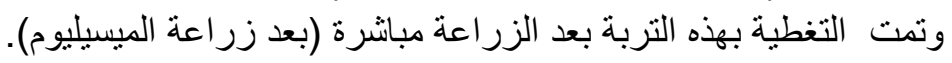


ز زر اعة الميسيليوم.

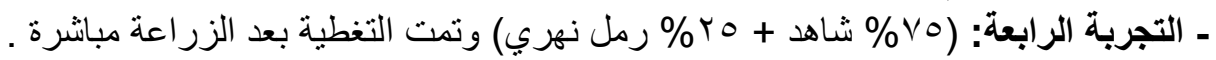

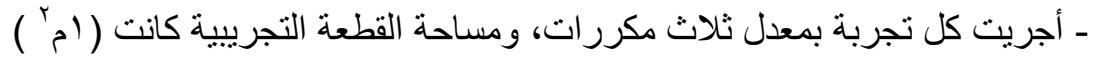

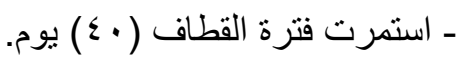
- عدد الأيام من زر اعة الميسيليوم حتى نهاية فترة القطاف كانت ( وإن للخواص الفيزيائية لتربة التغطية دور كبير على نمو وتطور الميسيليوم و على نهيئة الفطر

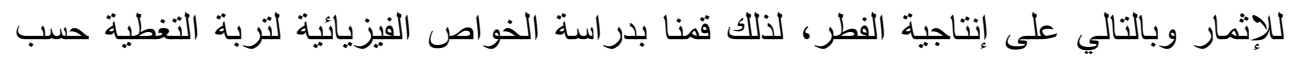

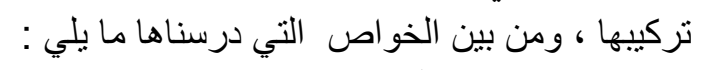

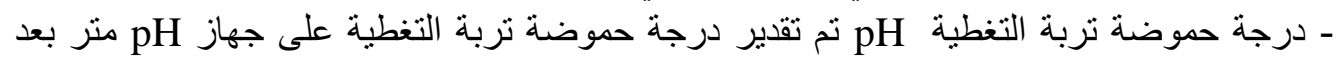

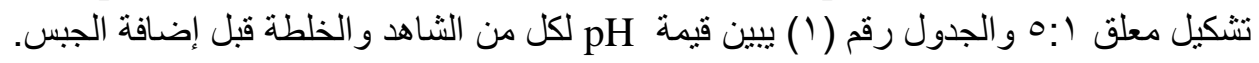

جدول رقم (1) يبين ال pH فقط بدون إضافة الجبس

\begin{tabular}{|c|c|}
\hline المتوسط & pH \\
\hline 0.1 & التورب \\
\hline $0 . \xi$ & التورب +هץ\% رمل نهري \\
\hline
\end{tabular}

Fayoum J. Agric. Res. \& Dev., Vol.23, No.2, July, 2009 


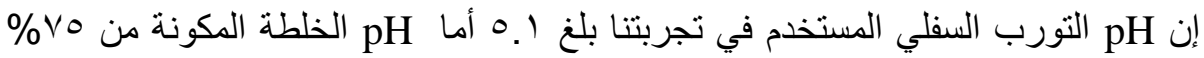

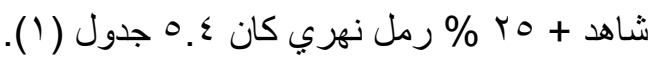

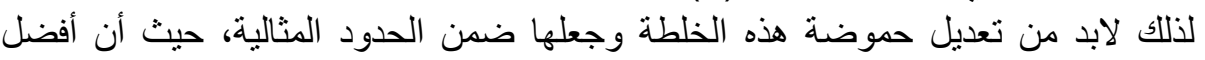

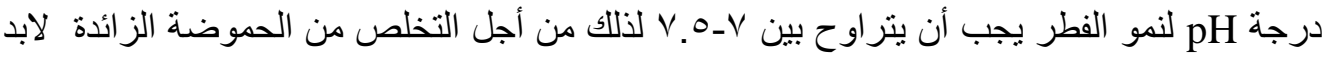

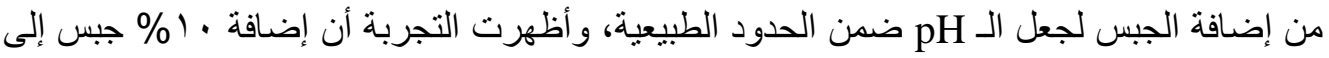

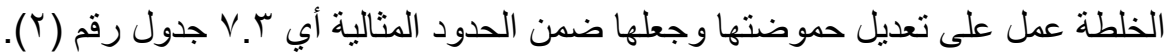
جدول رقم ( ( ) يبين الـ pH بعد إضعافة الجبس لتربة التغطية

\begin{tabular}{|c|c|}
\hline المتوسط & $\mathrm{pH}$ \\
\hline V.r & تورب سفلي + · (\% جبس شاهد \\
\hline$V . \varepsilon$ & • ا شاهد + 0ץ\% رمل نهري . \\
\hline
\end{tabular}

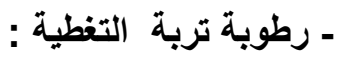
أخذنا عينات متعددة لتربة التغطية، ووضعت فئ في علب (كؤوس) ثم وزنت بدقة ووضعت في فرن

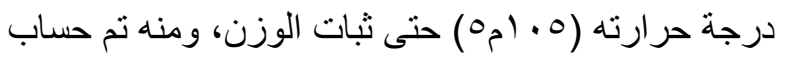

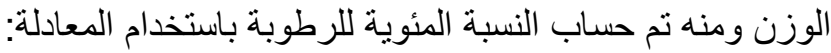

$$
\mathrm{W}=\underline{\mathrm{A} \times 100}
$$

B

حيث W رطوبة تربة التغطية ، A وزن الماء المفقود غ، وزن التربة الجافة . جدول رقم ب: يبين رطوبة تربة التغطية

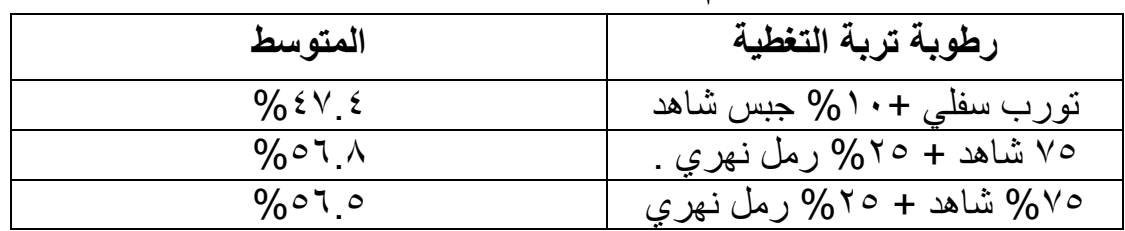

السعة الحقلية الانيا والعظمى : العزئ

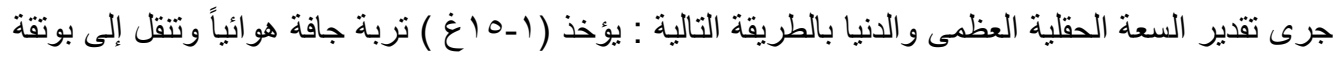

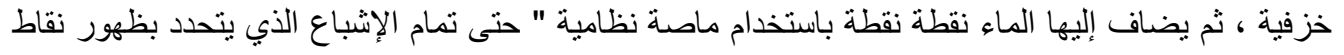

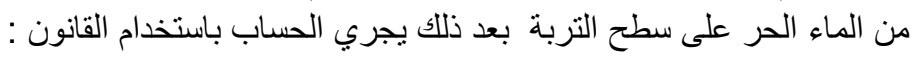

نسبة التشبع الكامل = كمية الماء المستخدمة فى عملية الإشباع ××

وزن التربة المستخدمة

السعة الحقلية = نسبة التشبع الكامل بالماء * ثابت التحويل من تشبع التربة الكامل إلى السعة الحقلية (بـ الثة . ). جدول رقم ؟ : يبين السعة الحقلية العظمى والدنيا لتربة التغطية

السعة الحقلية العظمى السعة الحقلية الدنيا

Fayoum J. Agric. Res. \& Dev., Vol.23, No.2, July, 2009 


\begin{tabular}{|c|c|}
\hline $11 . r$ & 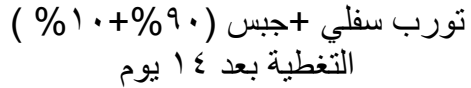 \\
\hline V.71** & 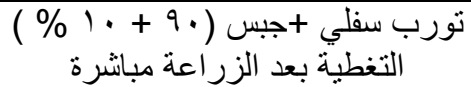 \\
\hline
\end{tabular}



ولدى تحليل نتائج التجارب إحصائياً وجدنا أن F المحسوبة أكبر من F الجدولية عند مستوى معنوية

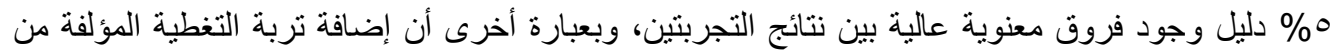

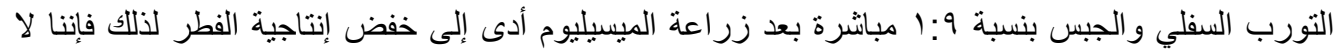

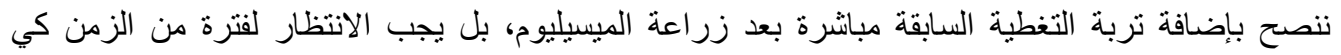

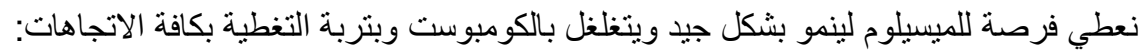

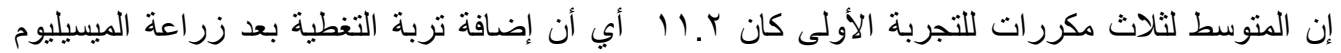

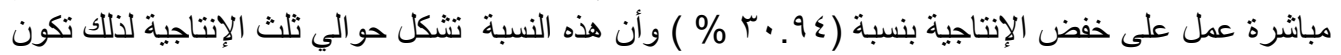
هذه الإضافة غير اقتصادية أبداً . الإنة

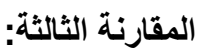

تمت فيها مقارنة إنتاجية التجربة الثانية (التي نتركب تربة التغطية فيها من هو\% من من الثاهد +

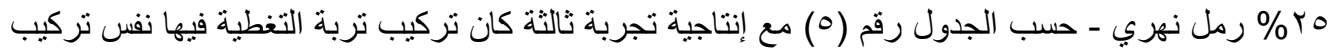

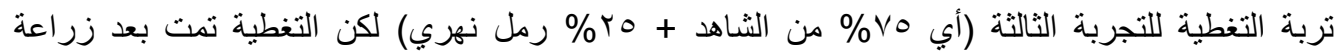

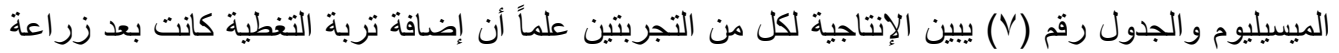

الميسيليوم مباثرة.

\begin{tabular}{|c|c|}
\hline المتوسط & تركيب الخلطة \\
\hline $11 . \ldots$ & 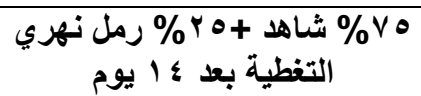 \\
\hline$\wedge .9 \mu^{* *}$ & 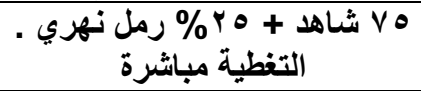 \\
\hline
\end{tabular}

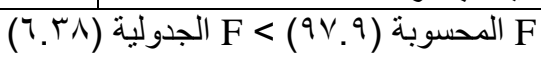

وبتحليل نتائج كل من التجربتين إحصائياً ، وجدنا أن F المحسوبة أكبر من F الجدولية هذا يعني أن

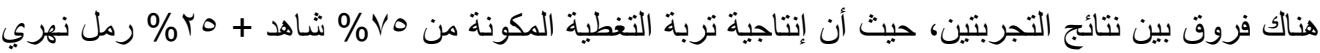

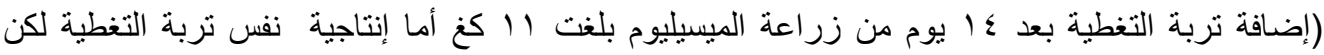

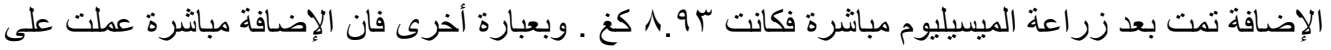

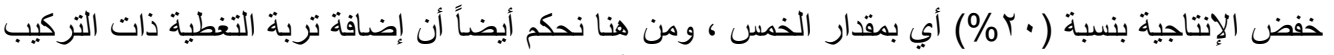

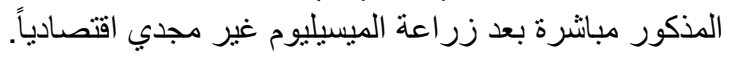

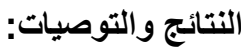

1 - يمكن استخدام مو اد بديلة للتورب بتركيب نربة التغطية مثل الرمل النهري.

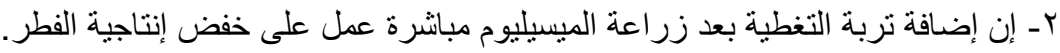



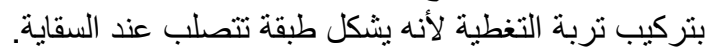



Fayoum J. Agric. Res. \& Dev., Vol.23, No.2, July, 2009 


$$
\begin{aligned}
& \text { هـ إن مو عد إضافة تربة التغطية ليس له تأثثر على الصفات الثكلية للأجسام الثمرية للفطر. }
\end{aligned}
$$

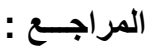

$$
\begin{aligned}
& \text { بوراس متيادي ( • 99 (1)، الزر اعة المحمية- مديرية الكتب و المطبو عات الجامعية- منشور ات جامعة دمشق. }
\end{aligned}
$$

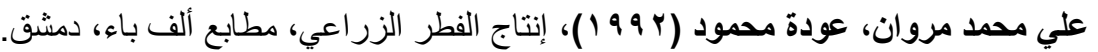

Vedder, P. (1971). Modern champignon, 352 p.

Gromof, H. F. (1995). CHAMPIGNON, Moscow, 176 p.

Vedder, P.(1968). RFARUNGEN Beim Pasteurisieren champignon, (77): 13-20.

Nair, P.N. (1976). STIUDIES ON RECYCLING SPENT COMPOST FOR MUSHROOM, 857-865 p.

Nair, P.N. (1977). AUSTRALIA USE OF SPENT COMPOST AS USING MATERIALS, 12-22 p.

Paterson, M. N. (1998). COMMERSIAL MUSHROOM DRAWING.

Defoshken, L.A. (1975). Mushroom, Moscow, Kolac, 135p.

Defoshken, L.A. (1989). Mushroom production, Moscow, Mer, 180 p.

\section{EFFECT OF CASING LAYER AND ITS APPLICATION DATE ON MUSHROOM PRODUCTION AND FRUIT BODIES}

\section{Fawaz Al-Haji Abboud}

Horticulture Depart. Faculty of Agriculture, Al- Forat Univ.

\section{ABSTRACT}

The present in restigatim amid at determing the different compositions of casting were bared in arailbiltey such as river sand as well as application dates of casting layer. Our results showed that two weeks after mycelium seeding was the best two for casting layer application has no effect on fruits bodies.

Key words: Casing layer, mycelium, mushroom, fruit bodies

$$
\begin{aligned}
& \text { هذا بحث جديد للاكتور السوري بالعربي مرفق }
\end{aligned}
$$

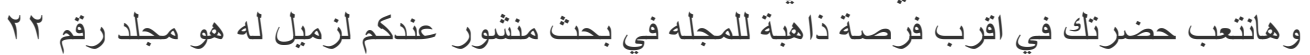

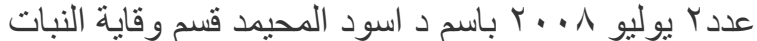

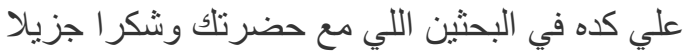

\section{الملخص الانجليزى قبل التعديل}

The experiment was conducted private green house during 2005 season. We used compost contained wheat straw, poultry waste and gypsum. 
The study purpose was to determination different compositions of casing layer based on available and cheapest materials such as river sand. Also, we studied different dates of casing layer application

Data analysis showed that best date of casing layer application was biweekly after mycelium seeding. Moreover, casing layer application after mycelium seeding caused a decreasing in mushroom production.

Fayoum J. Agric. Res. \& Dev., Vol.23, No.2, July, 2009 